(A) Check for updates

Cite this: Analyst, 2020, 145, 7320

\title{
Paper-based analytical devices for colorimetric detection of $S$. aureus and $E$. coli and their antibiotic resistant strains in milk $\dagger$
}

\author{
Muhammad Asif, (D) ${ }^{\text {a,b,c }}$ Fazli Rabbi Awan, (D) ${ }^{\text {a,b }}$ Qaiser Mahmood Khan, ${ }^{\text {a,b }}$ \\ Bongkot Ngamsom (D) ${ }^{c}$ and Nicole Pamme (D) *c
}

\begin{abstract}
Animal derived milk which is an important part of human diet due to its high nutritional value not only supports humans but also presents a growth environment for pathogenic bacteria. Milk may become contaminated with bacteria through udder infections or through contact within the dairy farm environment. Infections are treated with antibiotics, with $\beta$-lactams most commonly used in veterinary medicine. However, their frequent use leads to the emergence of $\beta$-lactam resistant bacterial strains, which causes difficulties in the treatment of infections in both humans and animals. Detection of pathogens as well as their antibiotic sensitivity is a pre-requisite for successful treatment and this is generally achieved with laboratory-based techniques such as growth inhibition assays, enzyme-linked immunosorbent assays (ELISA) or polymerase chain reactions (PCRs), which are unavailable in resource-limited settings. Here, we investigated paper-based analytical devices ( $\mathrm{PPADs}$ ) for the presumptive detection of Staphylococcus aureus (S. aureus) and Escherichia coli (E. coli) and their antibiotic resistant bacterial strains in milk samples. The $\mu$ PADs were fabricated on filter paper using wax printing, and then impregnated with chromogenic substrates, which reacted with bacterial enzymes to form coloured products. Limits of detection of $S$. aureus and $E$. coli and their antibiotic resistant strains in milk samples were found to be $10^{6} \mathrm{cfu} \mathrm{mL}^{-1}$. Enrichment of milk samples in a selective medium for $12 \mathrm{~h}$ enabled detection as low as $10 \mathrm{cfu} \mathrm{mL} \mathrm{L}^{-1}$. The paper devices tested on a set of 640 milk samples collected from dairy animals in Pakistan demonstrated more than $90 \%$ sensitivity and $100 \%$ selectivity compared to PCR, showing promise to provide inexpensive and portable diagnostic solutions for the detection of pathogenic bacteria in resource-limited settings.
\end{abstract}

Received 28th May 2020, Accepted 9th August 2020 DOI: 10.1039/d0an01075h rsc.li/analyst infections, i.e. mastitis, ${ }^{2}$ or via direct contact with contaminated materials. ${ }^{3}$ This contaminated milk is a potential source of transmission of foodborne pathogenic bacteria and its nutrient-rich environment allows bacteria to proliferate rapidly and produce toxins, thus making it an extremely vulnerable commodity for human health. ${ }^{4}$ In spite of strict quality controls, pasteurization of milk and improved health and wellbeing of dairy animals in developed countries, outbreaks of milk-borne illness have been reported. ${ }^{5-7}$ According to the Centers for Disease Control and Prevention (CDC): contaminated milk, and milk products, accounted for the most hospitalizations relating to food-borne illnesses. ${ }^{8}$ The European Union legislation (Regulation 853/2004) stipulates that only milk from healthy animals can be used for human consump-

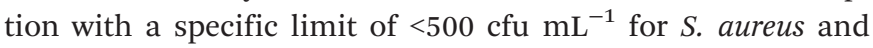
$<100 \mathrm{cfu} \mathrm{mL}^{-1}$ for $E$. coli (coliforms) in raw milk for drinking (Council Directive 92/46/EEC). ${ }^{9}$ The US Food and Drug Administration suggests lower levels of 10-100 organisms of $S$. aureus and $E$. coli in milk to be of public health concern. ${ }^{10}$ Compliance with such legislations can be achieved by constant 
vigilance over udder health and the quality of milk until it reaches the consumers. This is particularly challenging in resource-limited countries, where preventive measures are not always followed, ${ }^{8}$ and where reliable and affordable point-ofcare diagnostic methods are lacking.

Escherichia coli and Staphylococcus aureus are major milkborne pathogenic bacteria that cause a wide range of diseases including mastitis, food poisoning and gastroenteritis in both humans and animals. Mastitis, the most costly and common disease in dairy animals, is mainly treated with beta-lactam antibiotics such as penicillin and cephalosporin, typically for more than 3 days. ${ }^{11,12}$ Frequent and prolonged use of antibiotics in feedstock animals is one of the major reasons for the emergence of antibiotic resistant bacterial strains. Betalactam resistant strains of both $E$. coli and $S$. aureus have been reported, posing a growing threat for the effective treatment of infections related to these pathogens in both humans and animals. ${ }^{13,14}$

Identification of pathogens and their antibiotic sensitivity is a pre-requisite to tailoring effective prevention and treatment plans. This is usually achieved by cell-culture based methods and growth inhibition assays which are cumbersome, expensive and time-consuming. ${ }^{15,16}$ Alternatively, $\mathrm{PCR}^{16}$ and ELISA $^{17}$ techniques have been used for the detection of these pathogens in milk, but they require the availability of a dedicated laboratory facility, highly trained personnel, stable reagents, and multistep sample handling. Management of the logistical considerations associated with sample collection and transport to central laboratories is also required. Due to the lack of basic infrastructure, these techniques are of limited use in resource-poor settings. ${ }^{18}$ According to the World Health Organization (WHO), diagnostic tests for resource-limited environments should be affordable, sensitive, specific, userfriendly, rapid and robust, equipment-free, and deliverable to end-users (ASSURED). ${ }^{19}$ More recently, Land et al. proposed REASSURED with the addition of $\mathrm{R}$ (real-time connectivity) and $\mathrm{E}$ (ease of specimen collection and environmental friendliness) to the existing ASSURED, for the design of future diagnostic tests to address important priorities such as global health emergencies and antimicrobial resistance (AMR). ${ }^{20}$

Microfluidic paper-based analytical devices ( $\mu$ PADs) are a relatively new diagnostic platform that may satisfy the ASSURED and REASSURED criteria. $^{20,21}$ Being inexpensive, and simple to manufacture and operate, $\mu$ PADs have attracted significant interest as emerging alternatives to conventional tests, showing promise for scalable, low-cost monitoring, and user-operating analytical devices. The paper matrix, most commonly hydrophilic cellulose fibres, allows passive liquid transport through capillary forces. ${ }^{22,23}$ Hydrophobic barriers embedded into the fibre allow liquid flow to be confined. ${ }^{23} \mathrm{~A}$ range of methods has been reported for the fabrication of paper-based devices including inkjet printing, ${ }^{24}$ photolithography, ${ }^{21}$ cutting, ${ }^{25}$ stamping, ${ }^{26}$ screen printing ${ }^{27}$ and wax printing. ${ }^{28}$ Wax printing is probably the simplest and most rapid of these fabrication techniques, requiring only a commercially available office 'wax' printer, which operates like an ordinary office printer, but instead of ink, deposits wax on the paper. The printed paper is then heated to allow the wax to penetrate through the paper thickness, thus generating a hydrophobic barrier in the paper to enable control over fluid flow during an assay.

Recently, there have been reports on $\mu$ PADs for bacterial diagnostics. Henry's group developed $\mu$ PADs with colorimetric reactions between bacterial enzymes and chromogenic substrates, i.e. chlorophenol red- $\beta$-D-galactopyranoside (CPRG) to detect E. coli O157:H7, 5-bromo-6-chloro-3-indolyl caprylate for Salmonella typhimurium, and 5-bromo-4-chloro-3-indolyl-myoinositol phosphate for Listeria monocytogenes from ready-to-eat meat ${ }^{29,30}$ and from agricultural water samples. ${ }^{31}$ Exploiting the same motif, $\mu$ PADs were further developed for the detection of $\beta$-lactam resistance in $E$. coli in water samples by measuring the colour developed from the reaction between nitrocefin substrates and the bacterial secreted $\beta$-lactamase. ${ }^{30}$ A similar concept was also reported on $\mu$ PADs for $E$. coli BL21 detection from water samples. ${ }^{32}$

Globally, Pakistan is the fourth largest milk producing country, ${ }^{33}$ and $S$. aureus and $E$. coli as well as their antibiotic resistant strains can cause heavy losses to its dairy industry. Early and rapid screening systems can help minimise such losses and also help reduce the development of antibiotic resistance for mastitis treatment. The emerging Extended Spectrum Beta Lactamases (ESBLs) are not only able to inactivate narrow-spectrum antibiotics such as penicillins, and $1^{\text {st }}$ - and $2^{\text {nd }}$-generation cephalosporins, but also hydrolyse $3^{\text {rd }}, 4^{\text {th }}$ and $5^{\text {th }}$-generation $\beta$-lactam antibiotics such as ceftazidime (CAZ) and cefotaxime (CTX). ${ }^{34,35}$ Infections caused by ESBL-producing bacteria are very difficult to cure, have limited treatment options, and often result in treatment failure. ${ }^{36,37}$ Knowledge of antimicrobial susceptibility patterns of local bacterial population will significantly help clinicians with rapid identification of antibiotic resistant bacterial species and prescription of appropriate antibiotics in a timely manner.

In this study, $\mu$ PADs were explored for presumptive diagnosis of $E$. coli and $S$. aureus and their antibiotic-resistant strains in milk samples employing a range of chromogenic substrates (Table 1). For the first time, 5-bromo-6-chloro-3-indolyl phosphate $p$-toluidine salt (BCIP, magenta phosphate) and HMRZ-86 were employed on paper-based devices for the detection of $S$. aureus and ESBL-positive bacteria, respectively. The developed $\mu$ PADs were tested with 640 milk samples collected from healthy animals from dairy farms in Pakistan. By combining the various colorimetric assays on the $\mu$ PADs, a simultaneous indication of the presence of particular bacteria and their antibacterial resistance with readout can be achieved by the unaided eye or photographing via a smartphone.

\section{Experimental}

\section{Materials}

Bacterial strains of E. coli (NCTC 12241, 11560, 13351) and S. aureus (NCTC 12981, 12973) were obtained from Pro-Lab 
Table 1 Colour changing reactions employed herein to study the presence and antibiotic resistance of $E$. coli and S. aureus

\begin{tabular}{lllll}
\hline Substrate & Enzyme & Colour change & Indicative & Ref. \\
\hline CPRG & $\beta$-Galactosidase & Yellow to red-violet & The presence of $E$. coli & 29 and 31 \\
BCIP, magenta phosphate & Alkaline phosphatase & Colourless to purple-mauve & The presence of $S$. aureus & 38 \\
Nitrocefin & $\beta$-Lactamase & Yellow to red & Antimicrobial resistance to traditional $\beta$-lactams & 30,39 and 40 \\
HMRZ-86 & ESBL & Yellow to red & Antimicrobial resistance to extended $\beta$-lactams & 34, 35, and 41-43
\end{tabular}

Diagnostics (UK). Nitrocefin was obtained from Merck Millipore (UK). Chlorophenol red- $\beta$-D-galactopyranoside (CPRG), 5-bromo-6-chloro-3-indolyl phosphate $p$-toluidine salt (BCIP, magenta phosphate) or magenta phosphate, $\beta$-galactosidase, $\beta$-lactamase and rAPid alkaline phosphatase were all acquired from Sigma-Aldrich (UK). HMRZ-86 was purchased from Bio-Rad Laboratories (UK). Filter paper (Whatman grade 4) was bought from GE Healthcare Life Sciences (UK). Mueller-Hinton broth and Buffered Peptone Water broth were purchased from Oxoid Ltd, UK. Pasteurised cow's milk was purchased from local stores (Hull, UK).

\section{Preparation of bacterial culture}

Pure $\beta$-lactamase negative (NCTC 12241), $\beta$-lactamase positive (NCTC 11560) and ESBL positive (NCTC 13351) E. coli strains were cultured overnight in buffered peptone water (BPW) supplemented with vancomycin hydrochloride $\left(8 \mathrm{mg} \mathrm{L}^{-1}\right)$. Similarly, pure $\beta$-lactamase negative (NCTC 12981) and $\beta$-lactamase positive (NCTC 12973) S. aureus strains were grown overnight in Mueller-Hinton ( $\mathrm{MH}$ ) broth supplemented with $5 \%$ sodium hydroxide $(\mathrm{NaCl})$. Supplementation of the BPW medium with vancomycin hydrochloride renders the medium selective for $E$. coli, while addition of $5 \% \mathrm{NaCl}$ in $\mathrm{MH}$ broth makes the medium selective for $S$. aureus. ${ }^{31,44}$

\section{Fabrication of $\mu$ PADs}

Designs of the desired wax features were drawn in AutoCAD software (Student Version 2018). An array of $7 \mathrm{~mm}$ diameter circles with a $0.5 \mathrm{~mm}$ line thickness was printed on the Whatman paper using a wax printer (Xerox ColorQube). The paper was then wrapped in a single layer of aluminium foil and placed on a hot plate at $200{ }^{\circ} \mathrm{C}$ for $2-3 \mathrm{~min}$. The heat melted the wax and allowed it to pass through the paper to create a hydrophobic wax barrier. One side of the paper was sealed with masking tape to prevent leaking of reagents during an experiment.

\section{Preparation and deposition of chromogenic substrates in $\mu$ PADs}

Solutions of the chromogenic substrates were prepared in HEPES buffer (0.1 M HEPES, 0.1\% BSA, pH 7.5). CPRG for the detection of $E$. coli was made up as a $3 \mathrm{mM}$ solution according to Bisha et al., 2014. ${ }^{31}$ BCIP for the detection of $S$. aureus was prepared at $5.7 \mathrm{mM}$ (the maximum concentration at which the reagent can be dissolved in PBS without precipitation). For the detection of $\beta$-lactam resistant strains of $E$. coli and $S$. aureus, a solution of nitrocefin (1 $\mathrm{mM})$ was prepared as described by Boehle et al. $2017 .{ }^{30}$ HMRZ-86 was available in the soluble form in a $\beta$-LACTA test kit (Bio-Rad Laboratories) and was used for the detection of ESBL. For a point-of-care device to be used under field conditions, it is desired to have minimal user intervention. To this end, the chromogenic substrates were pre-deposited and dried onto the paper prior to use, in contrast to previous reports where they were added in liquid form. ${ }^{29,31}$ Prior to substrate deposition, the bottom of the printed paper was sealed with masking tape. Then, each chromogenic substrate solution $(6 \mu \mathrm{L})$ was deposited on the $\mu$ PADs and allowed to dry at room temperature for 5-10 min (visually inspected). The $\mu$ PADs were placed in a Petri dish covered with aluminium foil to prevent light exposure, and stored at $4{ }^{\circ} \mathrm{C}$ for 1-2 days prior to use.

\section{Optimisation of paper-based assays}

The colorimetric reactions for paper-based assays were optimised using enzyme solutions prepared in PBS; alkaline phosphatase $\left(0-80 \mathrm{mU} \mathrm{mL} \mathrm{m}^{-1}\right), \beta$-lactamase $\left(0-0.8 \mathrm{mU} \mathrm{mL}^{-1}\right)$, and

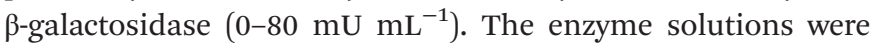
freshly prepared at the start of each experiment.

\section{Assays for bacterial culture, spiked milk and real milk samples}

Bacterial culture. Ten-fold serial dilutions of $E$. coli and $S$. aureus and their antibiotic resistant strains were prepared in their respective selective enrichment media. Lysis of $E$. coli was performed prior to testing using a probe sonicator (Diagenode Bioruptor/Sonicator UCD-200) at $22 \mathrm{kHz}$ for $30 \mathrm{~s}$ to liberate $\beta$-galactosidase according to the protocol described by Bisha et al. ${ }^{31}$ Alkaline phosphatase and $\beta$-lactamase are not endogenous enzymes and therefore, bacterial lysis was not conducted. To perform an assay on a $\mu \mathrm{PAD}, 35 \mu \mathrm{L}$ of pathogen suspension from each serial dilution was added to the pre-prepared $\mu \mathrm{PAD}$ and incubated at $37^{\circ} \mathrm{C}$ for 3-4 h.

Spiked milk samples. Overnight cultures of E. coli and $S$. aureus and their antibiotic resistant strains were used to prepare ten-fold serial dilutions in pasteurized cow's milk (local market, UK). A hundred microlitres of bacterial cell culture suspension was mixed with $900 \mu \mathrm{L}$ of milk sample. The solution was then further diluted (ten-fold) in milk. For quantification of colony forming units (cfu) per mL, $100 \mu \mathrm{L}$ from each serial dilution was plated in nutrient agar. Each dilution $(35 \mu \mathrm{L})$ was tested on the $\mu \mathrm{PAD}$ for colorimetric reactions. Previous studies reported that low volume enrichment $(<1 \mathrm{~mL})$ resulted in pathogen cell proliferation and an increase in their associated enzymes and therefore a more intense colour change and lower limit of detection were achievable. ${ }^{29}$ For this purpose, $900 \mu \mathrm{L}$ of selective enrichment broth was 
inoculated with $100 \mu \mathrm{L}$ of each serially diluted spiked milk sample. These enriched spiked milk samples were incubated at $37{ }^{\circ} \mathrm{C}$ for variable periods of time, i.e. $0,4,8$ or $12 \mathrm{~h}$. After incubation, $35 \mu \mathrm{L}$ from each enriched sample was tested on the $\mu \mathrm{PAD}$ with colorimetric reactions.

Raw milk samples. Following ethical clearance by the Institutional Ethical Committee (IEC) in the National Institute for Biotechnology and Genetic Engineering (NIBGE), Faisalabad (Pakistan), raw milk samples were collected from 640 dairy animals having apparently healthy udders (228 buffaloes and 412 cows in different dairy farms in rural areas of Faisalabad, Pakistan). Before sampling, initial few drops of milk were discarded, and teat ends were disinfected with cotton swabs soaked in $70 \%$ ethanol and allowed to dry. Each milk sample (5-10 mL) was collected directly in a sterile screw cap bottle from all quarters. The samples were kept on ice and transported to the laboratory for analysis. For enrichment of bacteria, $1 \mathrm{~mL}$ of the milk sample was diluted with $9 \mathrm{~mL}$ of BPW containing specific supplements and incubated at $37{ }^{\circ} \mathrm{C}$ for $12 \mathrm{~h}$ (Table S1, ESI $\dagger$ ). Specific supplement encourages growth of selective bacteria only. After incubation, the samples were tested using $\mu$ PADs for the detection of $S$. aureus and $E$. coli and their $\beta$-lactam resistant strains as discussed above.

\section{Visual detection and data analysis}

Colorimetric results were analysed through visual inspection of the $\mu \mathrm{PAD}$ at 3-4 h after sample deposition. The presence of $E$. coli in the samples was determined by a change in the colour of CPRG embedded in the $\mu$ PADs from yellow to redviolet. $^{29,31}$ Similarly, $S$. aureus was detected by a change in the colour of BCIP embedded in the $\mu$ PADs from colourless to mauve/purple. ${ }^{38}$ A change in the colour of nitrocefin ${ }^{24}$ and HMRZ-86 $6^{35,41-43,45}$ embedded in the $\mu$ PADs from yellow to red are the indicatives of $\beta$-lactamase and ESBL positive bacteria, respectively.

Semi-quantitative analysis of the colorimetric end results was performed according to the previously reported protocol by Boehle et al. ${ }^{30}$ Briefly, following the assay, Petri dishes containing the $\mu$ PADs were placed inside a light box $(16 \mathrm{~cm} \times$ $16 \mathrm{~cm} \times 16 \mathrm{~cm})$ to avoid light interference during image capture. The camera part of the smart phone (Vodafone $890 \mathrm{~N}$, operated with flash) was placed between the slit of the light box $(2 \mathrm{~cm} \times 5 \mathrm{~cm})$ to obtain images. The images were analysed using ImageJ freeware (National Institute of Health, USA), following the protocol previously described. ${ }^{24}$ Initially, the images were processed through a Red Green Blue (RGB) stack and the Green channel was selected as it is the complementary colour of red, which is the end point colour of all reactions except the $S$. aureus experiment which was mauve/purple. Although the complementary colour of mauve/purple is yellow, it gave a relatively high sensitivity with the green image amongst the RGB stack. Therefore, it was also analysed through the green channel. Next, the image was inverted. Circles were drawn to outline the measurement areas within the reaction zones. Utilising the "Measure" tab under
"Analyze", the average colour intensity within the defined areas was obtained and further analysed with Microsoft Excel. The colour intensity of $\mu$ PADs containing water was also analysed as a blank: the colour intensity of $\mu$ PADs containing samples was normalized by subtracting the colour intensity of $\mu$ PADs containing water. Normalised data were processed in Microsoft Excel to obtain mean and standard deviations from three separate repeats $(n=3)$.

\section{UV-vis spectrophotometric detection of colorimetric reactions}

UV-vis spectrophotometric analysis of colorimetric reactions employed for $\mu$ PADs was performed on the same reactions using microtitre plates and a UV-vis plate reader (NanoDrop ${ }^{\mathrm{TM}}$ Lite Spectrophotometer, Thermofisher Scientific). For this purpose, $100 \mu \mathrm{L}$ of ten-fold serial dilutions of $S$. aureus and E. coli and their $\beta$-lactam resistant bacterial strains were reacted with $100 \mu \mathrm{L}$ of their respective chromogenic substrates whose concentrations were similar to those used on $\mu$ PADs. The microtiter plate was then incubated at $37^{\circ} \mathrm{C}$ for $2 \mathrm{~h}$. Following this, absorbance at various wavelengths was measured; $595 \mathrm{~nm}$ for the CPRG reaction, $405 \mathrm{~nm}$ for the BCIP reaction, and $490 \mathrm{~nm}$ for the nitrocefin and HMRZ-86 reaction.

\section{Polymerase chain reactions (PCR)}

DNA was extracted from enrichment broth using a GeneJET Genomic DNA Purification Kit according to the manufacturer's instructions. A Nano-drop system (ND-2000C, Thermofisher Scientific) was employed to quantify the concentration and purity of the extracted DNA. The primers used during PCR are summarised in Table S2, ESI. $\dagger$ All the reactions were carried out to a final volume of $50 \mu \mathrm{L}$ under the following conditions. Initial denaturation at $94{ }^{\circ} \mathrm{C}$ for $2 \mathrm{~min}$, followed by 35 cycles of denaturation at $94{ }^{\circ} \mathrm{C}$ for $1 \mathrm{~min}$, annealing (at the temperature summarised in Table S2, ESI $\dagger$ ) for $1 \mathrm{~min}$, and extension at $72{ }^{\circ} \mathrm{C}$ for $2 \mathrm{~min}$. Final extension was performed at $72{ }^{\circ} \mathrm{C}$ for $10 \mathrm{~min}$ to complete the reaction. Amplified PCR products were detected by electrophoresis on $1.5 \%$ agarose gel and visualised using a gel documentation system (Gel Doc ${ }^{\mathrm{TM}}$ EZ Imager, BioRAD) and photographed. A GeneRuler $1 \mathrm{~kb}$ DNA ladder (Thermo Scientific) was included in each run.

\section{Results and discussion}

\section{Paper-based assays employing colorimetric reactions between bacterial enzymes and their corresponding chromogenic substrates}

The development of the paper-based assays initially involved the use of enzyme solutions, rather than enzymes derived from the bacteria, to confirm the feasibility of enzyme-substrate reactions on the paper matrix. For optimisation of the reaction conditions, different dilutions of pure bacterial enzymes were freshly prepared at the start of each experiment. The lowest $\beta$-galactosidase concentration to produce a distinguishable colour change from yellow to red-violet was 0.02 
$\mathrm{U} \mathrm{mL}^{-1}$ (Fig. 1S(a), $\mathrm{ESI}_{\dagger}^{\dagger}$ ), comparable to $0.03 \mathrm{U} \mathrm{mL}^{-1}$ reported for $\beta$-galactosidase. ${ }^{46}$ The lowest enzyme concentration to show a distinctive colour change for $\beta$-lactamase assay was $0.1 \mathrm{mU} \mathrm{mL}^{-1}$ (Fig. 1S(b), ESI $\dagger$ ). The discrepancy with the value of $10 \mathrm{mU} \mathrm{mL}{ }^{-1}$ reported by Boehle et al. ${ }^{30}$ may plausibly be due to different sources of beta-lactamase employed for the reaction.

For $S$. aureus detection, the reaction between solutions of BCIP and alkaline phosphatase solution was first attempted on paper. Utilising $3 \mathrm{mM}$ BCIP, a characteristic colour change from colourless to mauve/purple was successfully observed at $\geq 0.006 \mathrm{U} \mathrm{mL}^{-1}$ of alkaline phosphatase (Fig. 1S(c), ESI $\dagger$ ). This demonstrates a novel paper-based assay for $S$. aureus detection via bacterial alkaline phosphatase and its corresponding chromogenic substrate BCIP (magenta phosphate).

\section{Testing of the developed $\mu$ PADs with bacterial culture}

Having successfully developed $\mu$ PADs for the detection of bacterial enzymes from enzyme solutions, the devices were next tested with live bacteria populations obtained from cell cultures in their respective growth media. Ten-fold serial dilutions of different strains of $E$. coli and $S$. aureus were prepared in their respective selective broths and reacted with their relevant chromogenic substrate on the $\mu$ PADs.

In order to determine the presence of $\beta$-galactosidase, $E$. coli was lysed prior to testing on the developed paper device as $\beta$-galactosidase is produced inside $E$. coli cells and is not secreted into the surrounding medium. A distinctive colour change from yellow to red-violet when reacting with CPRG was observed at an $E$. coli concentration of $\geq 3.6 \times 10^{6} \mathrm{cfu} \mathrm{mL}^{-1}$ (Fig. S2(a), ESI $\dagger$ ), in good agreement with the $3.8 \times 10^{6} \mathrm{cfu}$ $\mathrm{mL}^{-1}$ value detected on $\mu$ PADs developed by Boehle et al. ${ }^{30}$

In contrast to $\beta$-galactosidase, alkaline phosphatase is excreted from $S$. aureus cells into the surrounding medium. The reaction between $S$. aureus secreted alkaline phosphatase and BCIP was therefore carried out without cell lysis (Fig. S2(b), ESI $\dagger$ ) employing the same device shown in Fig. S1(c), ESI. $\dagger$ A distinguishable colour change from colourless to mauve/purple was observed at a concentration exceeding $3.6 \times 10^{6} \mathrm{cfu} \mathrm{mL}^{-1}$. To the best of our knowledge, this is the first time the detection of $S$. aureus was demonstrated on a paper device based on the reaction between bacteria secreted enzyme alkaline phosphatase and 5-bromo-6-chloro-3-indolyl phosphate $p$-toluidine salt.

Next, the efficiency of the developed $\mu$ PADs on detecting the $\beta$-lactam resistant strain of $E$. coli was examined using the colorimetric reaction between nitrocefin and beta-lactamase to produce a characteristic colour change from yellow to red. No cell lysis was performed prior to the reaction, even though a marginal $5 \%$ increase in colour intensity on $\mu$ PADs tested with lysed $E$. coli was observed when compared to that of intact cells. $^{30}$ As expected, no colour change occurred for the $\beta$-lactam susceptible strain of $E$. coli, where no $\beta$-lactamase was produced by the bacterial enzyme (Fig. S3(a), ESI $\dagger$ ). For the $\beta$-lactam resistant strains, a colour change occurred at concentrations $\geq 10^{6} \mathrm{cfu} \mathrm{mL}^{-1}$, in good agreement with $\geq 3.8 \times 10^{6}$ cfu $\mathrm{mL}^{-1}$ bacteria reported from $\mu$ PADs tested with different $\beta$-lactam resistant bacteria in wastewater and sewage. ${ }^{24}$ The same device tested with a $\beta$-lactam resistant strain of $S$. aureus detected the colour change at $\geq 1.3 \times 10^{6} \mathrm{cfu} \mathrm{mL}^{-1}$ (Fig. S3(b), ESI†).

The experiments confirmed the feasibility of $\mu$ PADs for $E$. coli and the $\beta$-lactam resistant strain of $E$. coli, as well as feasibility for the detection of $S$. aureus employing the reaction between their secreted alkaline phosphatase and the chromogenic BCIP substrate. In addition, a $\beta$-lactam resistant strain of $S$. aureus was effectively detected using the nitrocefinembedded $\mu \mathrm{PAD}$. Distinctive colour changes were observed in all cases at bacterial levels of $\geq 10^{6} \mathrm{cfu} \mathrm{mL}^{-1}$.

\section{Cross reactivity study of $\mu$ PADs for $S$. aureus and $E$. coli}

The colorimetric assays employed for the developed paper devices utilised enzymes which could also be produced by other bacteria, and hence a compromised specificity might be expected when performed under field conditions. In laboratory settings, specific supplements can be added into the enrichment media in order to promote the growth of target bacteria, whilst simultaneously inhibiting the growth of other competing bacteria. Herein, vancomycin hydrochloride was utilised to support the growth of $E$. coli, and to suppress the growth of $S$. aureus. Similarly, the high salt content present in $\mathrm{MH}$ broth only permits $S$. aureus to grow. A cross-reactivity study between the two assays was carried out after incubating the bacteria in selective enrichment broths. The colour change was only observed when the correct pair of bacterial enzyme and specific substrate was present, with no false positive results found from the two bacterial species (Fig. 1). Although cross reactivity can be eliminated in laboratory analysis using a growth inhibitor to suppress competing bacteria, this can be problematic in field tests and false positive results are inevitable. Nevertheless, the method can still be suitable as an initial screening test providing impetus for further testing and confirmation to be conducted. Further investigations will include protocols to minimise other related contaminating bacteria in the sample using selective enrichment media.

\section{$\mu$ PADs for the differentiation of $\beta$-lactam resistant and ESBL resistant bacteria}

Next, we aimed to develop paper-based assays for the detection of ESBL bacteria which not only show resistance to penicillins, such as cephalosporins and aztreonam, but also to other classes of antibiotics, such as aminoglycosides, cotrimoxazole, tetracycline and fuoroquinolones.

Nitrocefin was reported as a suitable substrate for the detection of ESBL bacteria. A colour change from yellow to red could be observed on the developed $\mu \mathrm{PAD}$ when pathogen concentrations exceeded $10^{6} \mathrm{cfu} \mathrm{mL}^{-1}$ for both $\beta$-lactam resistant E. coli and ESBL resistant E. coli (Fig. S4(a), ESI $\dagger$ ) as nitrocefin cannot differentiate between these two groups. ${ }^{36}$ As such, a specific chromogenic cephalosporin, HMRZ-86, was herein exploited as a selective chromogenic substrate embedded on the $\mu \mathrm{PAD}$ to detect ESBL-resistant bacteria. A carboxypropyl- 


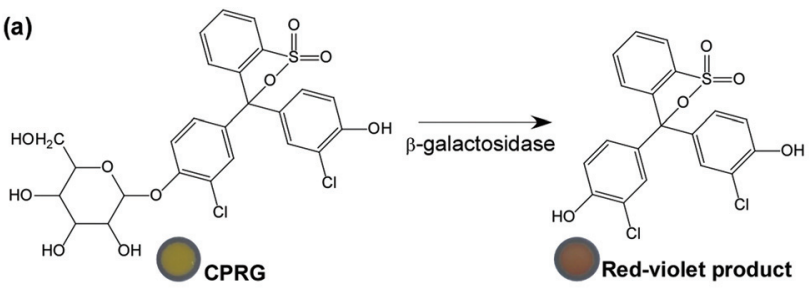

(b)
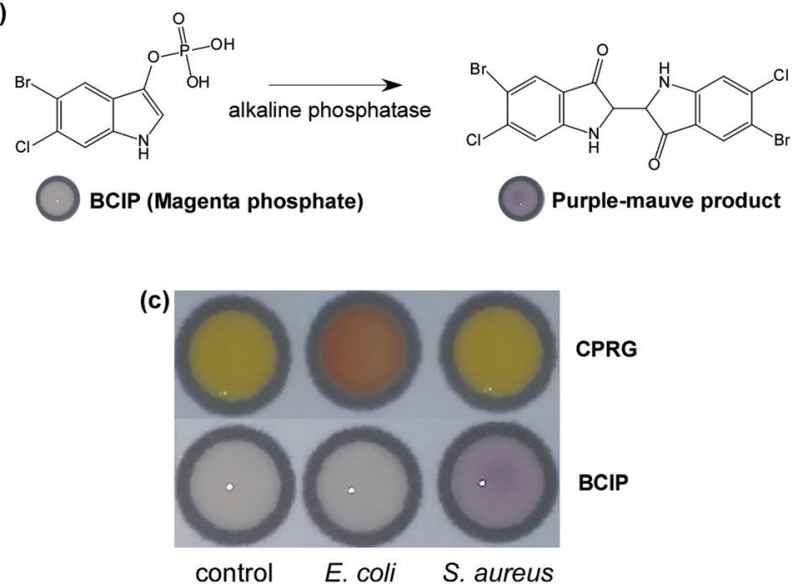

Fig. 1 Cross reactivity study for assessing the selectivity of each enzyme-substrate pair. (a) A reaction between the CPRG substrate and the enzyme $\beta$-galactosidase from $E$. coli yields a colour change from yellow to red-violet. (b) A purple-mauve colour product is afforded from the reaction between the BCIP substrate and the enzyme alkaline phosphatase from S. aureus. (c) $\mu$ PADs embedded with CPRG (top row) and BCIP (bottom row) tested with control (left-hand column), E. coli (middle column) and S. aureus (right-hand column). Colour change was observed only when a specific substrate-enzyme pair was present. Level of bacteria $=10^{6} \mathrm{cfu} \mathrm{\textrm {mL } ^ { - 1 }}$.

oxyimino group that binds to the side chain at position 7 in compound protects the $\beta$-lactam ring from a range of $\beta$-lactamases, but not from extended-spectrum $\beta$-lactamases (ESBLs) ${ }^{45}$ In contrast to nitrocefin embedded $\mu$ PADs, a colour change from yellow to red only occurred from the presence of ESBL-resistant E. coli at concentrations exceeding $10^{6} \mathrm{cfu} \mathrm{mL}^{-1}$ (Fig. S4(b), ESI $\dagger$ ). This development can be applied to real samples where differentiation of antibiotic resistant E. coli strains can prove to be crucial.

The sensitivity of the paper-based reactions performed on the developed $\mu$ PADs was validated against the UV-visible spectrophotometry results obtained from the same liquid-phase reactions conducted in conventional microtitre plates. A comparable level of $10^{6} \mathrm{cfu} \mathrm{mL}^{-1}$ bacteria detection observed from the absorbance values of the spectrophotometric assay confirming the viability of the developed $\mu$ PADs (Fig. S5-S7, ESI $\dagger$ ), and demonstrating a cost-effective approach of $\mu$ PADs coupled with a smart phone for the detection of bacteria in samples without the need for sophisticated laboratory equipment and trained staff.

\section{$\mu$ PADs for the analysis of bacterial spiked-milk samples}

Having demonstrated the viability of the paper devices for the detection of $E$. coli and $S$. aureus and their antibiotic resistant strains from bacterial culture media, the $\mu$ PADs were next tested with milk samples spiked with bacteria in a range of ten-fold serial dilutions.

First, the $\mu \mathrm{PAD}$ embedded with BCIP was investigated with milk samples spiked with $S$. aureus. A colour change from the reaction between $S$. aureus secreted alkaline phosphatase and BCIP was visually detectable at a concentration exceeding $4.5 \times$ $10^{6} \mathrm{cfu} \mathrm{mL} \mathrm{m}^{-1}$ (Fig. 2a), similar to the result previously obtained from $S$. aureus in culture media. The nitrocefin reaction also worked well distinguishing between $\beta$-lactam susceptible and $\beta$-lactam resistant strains of $S$. aureus spiked into milk samples (Fig. 2b). The resistant strain of $S$. aureus revealed a red colour at concentrations exceeding $4.5 \times 10^{6} \mathrm{cfu} \mathrm{mL}^{-1}$. These results showed the successful paper-based detection of $S$. aureus and its $\beta$-lactam resistant strain from spiked milk samples, which can potentially be utilised for detecting such pathogenic bacteria from real milk samples and other complex matrices.

(a)

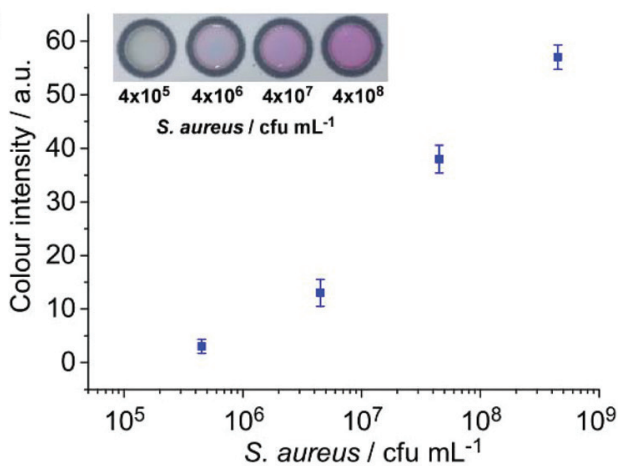

(b)
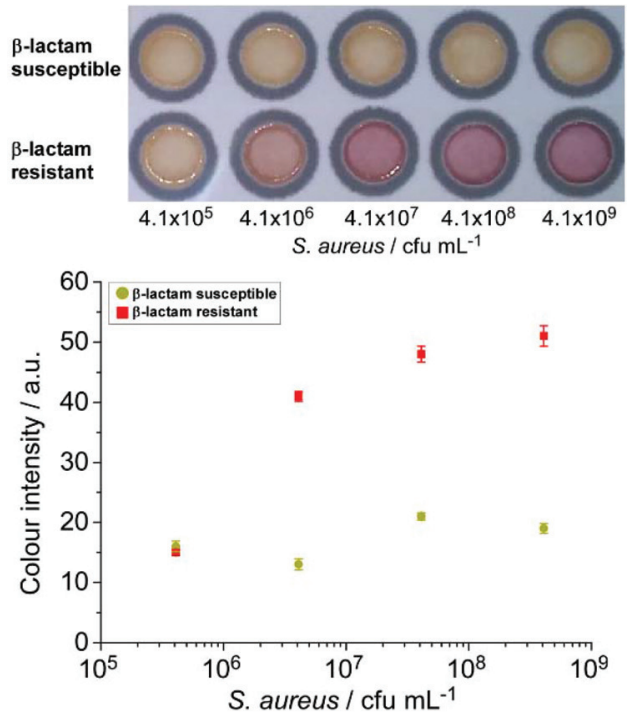

Fig. 2 (a) Reaction on the $\mu$ PAD between the BCIP substrate $(5.7 \mathrm{mM})$ and alkaline phosphatase excreted from $S$. aureus spiked into milk. A

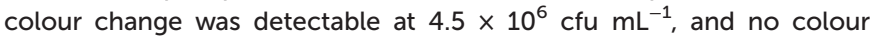
change was observed at $4.5 \times 10^{5} \mathrm{cfu} \mathrm{mL}^{-1}$. (b) Reaction on $\mu \mathrm{PAD}$ between the nitrocefin substrate and live bacteria of $\beta$-lactam resistant and $\beta$-lactam susceptible strains of $S$. aureus. Only the resistant strain yields a colour change when concentrations exceed $10^{6} \mathrm{cfu} \mathrm{\textrm {mL } ^ { - 1 }}$ $(n=3)$. 
The nitrocefin-embedded $\mu \mathrm{PAD}$ tested with $E$. coli spiked into milk samples showed a colour change to red for the resistant strain at a concentration $\geq 2.4 \times 10^{6} \mathrm{cfu} \mathrm{mL}^{-1}$ (Fig. 3), similar to the observation from the culture broth. Boehle et al. also detected a colour change in their nitrocefin embedded $\mu$ PADs tested with wastewater and sewage with $\geq 3.8 \times 10^{6} \mathrm{cfu} \mathrm{mL}^{-1}$ bacteria, but not with lower concentrations. $^{30}$ This shows the versatility of the paper-based $\beta$-lactamase-nitrocefin assays for the detection of $\beta$-lactam

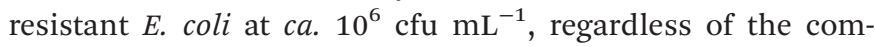
plexity of the matrices.

The assessment of the HMRZ-86 impregnated $\mu$ PAD with spiked milk samples also demonstrated the specificity to the EMBL-resistant strain of $E$. coli at a similar visual detection level of $2.7 \times 10^{6} \mathrm{cfu} \mathrm{\textrm {mL } ^ { - 1 }}$ as found in pure culture samples (Fig. 4).

However, the reaction between CPRG and $\beta$-galactosidase from lysed $E$. coli was not successfully tested with spiked milk samples (Fig. S8, ESI $\dagger$ ). It is postulated that $\beta$-galactosidase released by the bacteria might have hydrolysed a large amount of lactose contained in the milk samples, and therefore only a small quantity of $\beta$-galactosidase was available to react with embedded CPRG.

Following on, pre-enrichment of spiked milk samples was attempted in order to supply nutrients and to encourage bacteria growth over a period of a few hours prior to testing. The supplements contained within the enrichment media selectively promote the growth of target bacteria, whilst simultaneously inhibiting the growth of other competing bacteria. Thus, the desired bacteria can be brought to a concentration level that is detectable through the colorimetric reaction on the $\mu$ PADs.

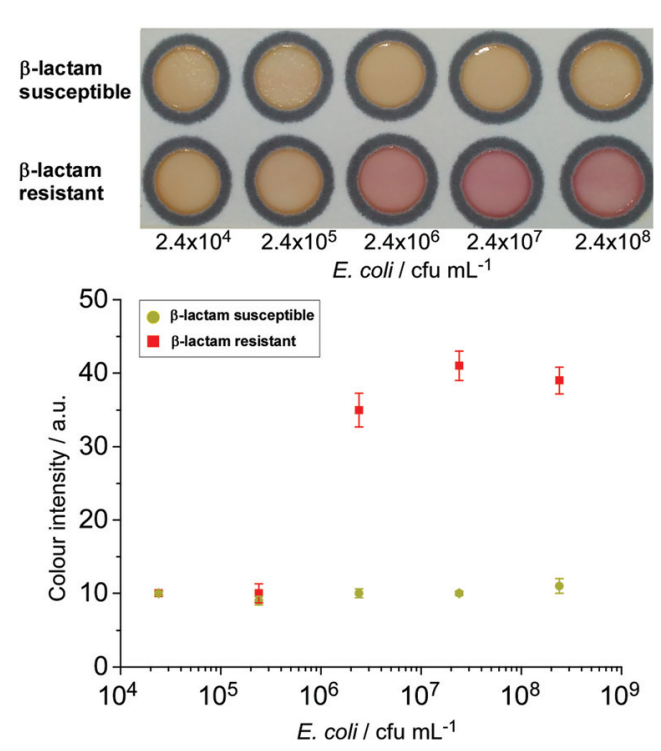

Fig. 3 Reaction on the $\mu$ PAD between the nitrocefin substrate and live bacteria of $\beta$-lactam resistant and $\beta$-lactam susceptible strains of $E$. coli. Only the resistant strain yielded a colour change when concentrations

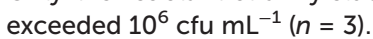
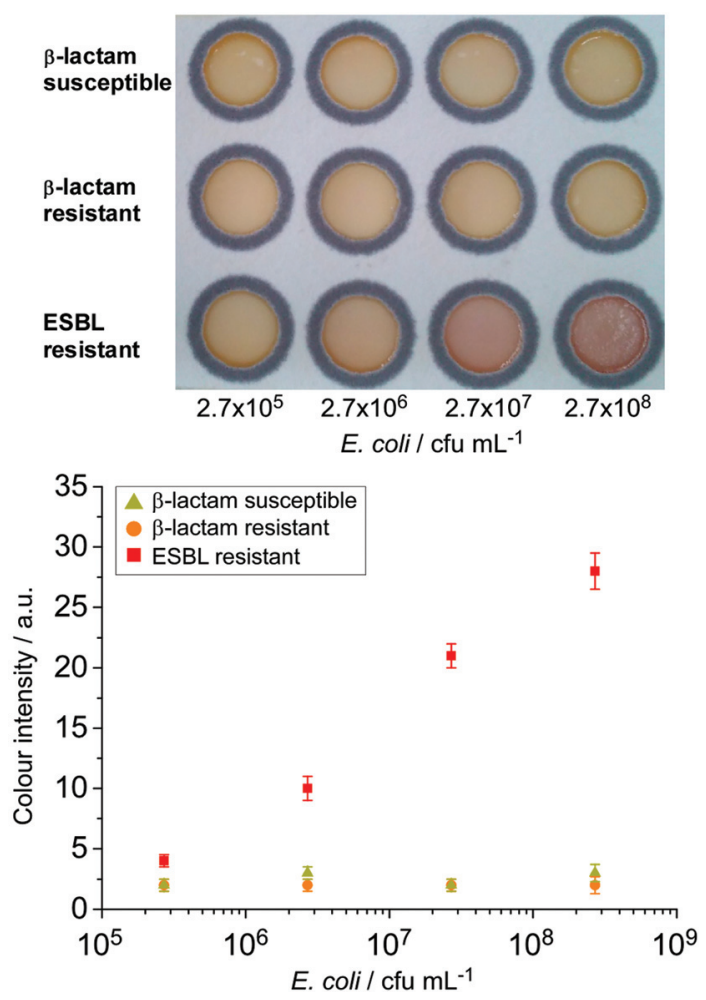

Fig. 4 Detection of ESBL E. coli from spiked milk samples employing the HMRZ-86 impregnated HPAD. A distinctive colour change from yellow to red was observed from the ESBL resistant strain of E. coli at 2.7 $\times 10^{6} \mathrm{cfu} \mathrm{mL}^{-1}(n=3)$.

Fig. 5 depicts the colorimetric results obtained from milk samples spiked with $E$. coli and $S$. aureus and their antibiotic resistant strains after pre-enrichment. Levels of bacteria as low as $10 \mathrm{cfu}$ per $1 \mathrm{~mL}$ of the spiked milk sample could be detected following 12 or $16 \mathrm{~h}$ of pre-enrichment in their respective selective broths. This suggests that the sensitivity of the paper-based assays can be vastly improved by including a bacterial pre-enrichment step. Pre-enrichment amplifies the analyte target, and when combined with selective growth media, it reduces the growth of unwanted bacteria in samples that could contribute to false positive results as also reported previously. ${ }^{24,31}$ This step only required an incubator, which is commonly used in microbiology laboratories. With further investigations, a suitable pre-concentration step can be included in the platform for field tests. The final detection performed on $\mu$ PADs can offer a simple, cost-effective, and easyto-interpret solution for the screening of major milk borne pathogens. The entire process, overnight pre-enrichment and colorimetric detection, can be performed within one day, and it allows the detection of bacterial contamination as low as 10 cfu $\mathrm{mL}^{-1}$ from the initial sample.

\section{$\mu$ PADs for the analysis of bacteria in raw milk samples}

The ultimate goal of this present study was to develop a simple, cost-effective and user-friendly device for the detection 

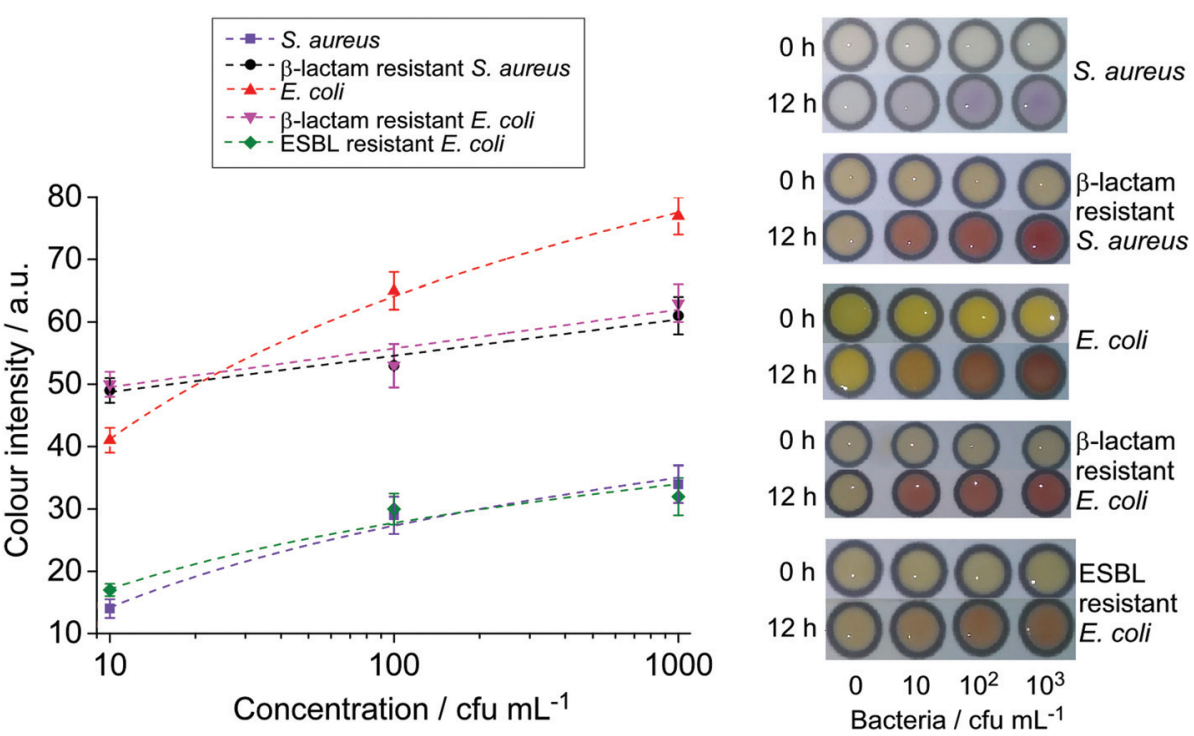

Fig. 5 Photographs and colour intensity analysis of milk samples spiked with various bacteria after $12 \mathrm{~h}$ enrichment $(n=3)$.

of pathogenic bacteria causing mastitis suitable for resourcepoor areas in the developing countries. The viability of the developed paper devices was therefore examined for the detection of $S$. aureus and E. coli with raw milk collected from a group of cattle and buffaloes in Pakistan. The samples were collected from healthy animals from the field. Due to very low level of bacteria from the samples, pre-enrichment with selective media was required to increase the number of bacteria to meet with the detectable level of the paper devices ( $c a .10^{6} \mathrm{cfu}$ $\mathrm{mL}^{-1}$ ) previously observed from bacterial spiked milk samples. In order to achieve this, a milk sample $(10 \mathrm{v} \%)$ was mixed with selective media ( $90 \mathrm{v} \%$ ) and incubated at $37{ }^{\circ} \mathrm{C}$ for $12 \mathrm{~h}$. This step not only increased the bacterial level, but also diluted the lactose concentration in the samples, thereby diminishing the consequent competing lactose hydrolysis which was problematic in the $\beta$-galactosidase-CPRG reaction previously observed in $E$. coli spiked milk samples. Subsequently, the pre-enriched samples were analysed on $\mu$ PADs and PCR gene analysis was conducted for result confirmation (Fig. 6a and b).

Out of 640 milk samples, $\mu$ PADs detected 77 samples with E. coli positive (84 samples confirmed by PCR), and 129 samples with $S$. aureus positive (143 confirmed by PCR) as summarised in Table 2. These results suggested that the sensitivity of our developed $\mu$ PADs was higher than $90 \%$. The positive results obtained on $\mu$ PADs also showed positive from PCR, indicating that the $\mu$ PADs were also $100 \%$ specific. (a)

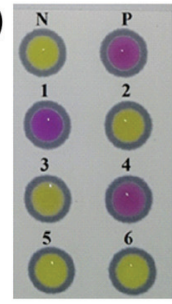

(c)

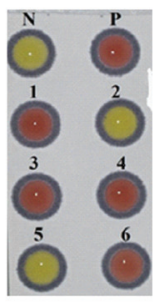

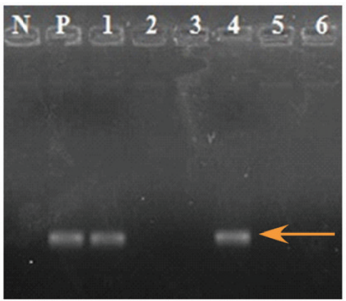

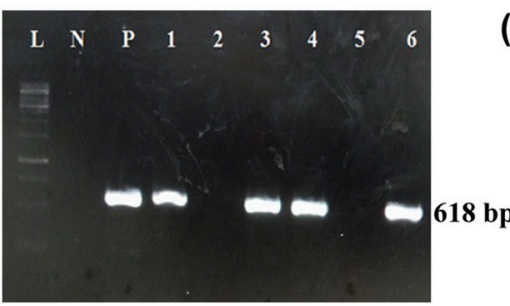

(b)

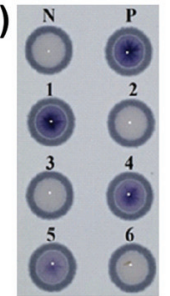

(d)

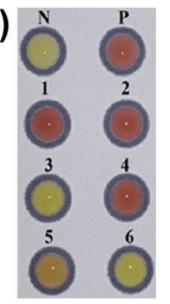

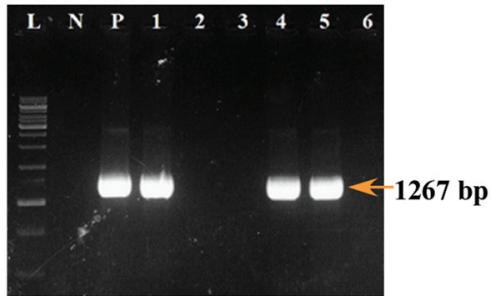

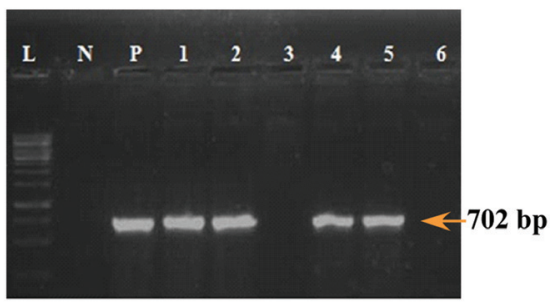

Fig. 6 Left: Detection of pathogenic bacteria employing $\mu$ PADs; (a) E. coli. (b) S. aureus. (c) Beta-lactam resistant E. coli. (d) Beta-lactam resistant S. aureus. $\mathrm{N}=$ negative control that contains enrichment broth without any sample/bacteria; $\mathrm{P}=$ positive control that contains enrichment broth with pathogenic bacteria or their $\beta$-lactam resistant strains; $1-6=$ samples collected from field. Right: gel electrophoresis of various PCR products; $\mathrm{N}=$ negative control that contains no DNA template; $\mathrm{P}=$ positive control that contains DNA of pathogenic bacteria or their $\beta$-lactam resistant strains; Lanes 1-6 = samples collected from the field. 
Table 2 Comparison of the results from $\mu$ PADs and PCR for the detection of $E$. coli and $S$. aureus from raw milk $(n=640)$

Positive samples

\begin{tabular}{lll}
\cline { 2 - 3 } Bacteria & $\mu \mathrm{PAD}$ & $\mathrm{PCR}$ \\
\hline E. coli & $77(12 \%)$ & $84(13.1 \%)$ \\
S. aureus & $129(20.2 \%)$ & $143(22.3 \%)$
\end{tabular}

Table 3 Comparison of the results from $\mu$ PADs and PCR for the detection of $E$. coli and $S$. aureus from raw milk $(n=640)$

\begin{tabular}{lll}
\hline & \multicolumn{2}{l}{ Positive samples } \\
\cline { 2 - 3 } Bacteria & $\mu \mathrm{PAD}$ & PCR \\
\hline$\beta$-Lactam resistant E. coli & $52 / 77(67.5 \%)$ & $52 / 77(67.5 \%)$ \\
$\beta$-Lactam resistant $S$. aureus & $81 / 129(62.7 \%)$ & $81 / 129(62.7 \%)$
\end{tabular}

Beta-lactam is the most widely used class of antibiotics in veterinary medicine. As a result, $\beta$-lactam resistant pathogens are very common in livestock. For the detection of $\beta$-lactam resistance in the E. coli- and $S$. aureus-positive milk samples, enrichment cultures were sub-cultured in BPW supplemented with cefotaxime $\left(2 \mu \mathrm{g} \mathrm{mL}^{-1}\right)$ and tested on nitrocefin embedded $\mu$ PADs. Beta-lactam resistance in the same samples was also confirmed by PCR through amplification of the blaTEM gene (Fig. $6(\mathrm{c}$ and d)). The $\mu$ PAD detected $\beta$-lactam resistant pathogens in $67 \%$ and $62.7 \%$ of $E$. coli and $S$. aureus isolates, respectively, without false positive results confirmed by PCR (Table 3). Therefore, the $\mu \mathrm{PAD}$ accurately detected $\beta$-lactam resistant isolates.

We have shown a successful implementation of paperbased colorimetric assays for the detection of $E$. coli and $S$. aureus and $\beta$-lactam resistant strains in milk samples that could be achieved within a day. The present setup required no sophisticated equipment, and yet yielded similar sensitivity and selectivity to the molecular diagnostic technique of PCR for results obtained from 640 raw milk samples. In developing countries like Pakistan, dairy farms are located in remote and resource limited areas and local veterinary diagnostic laboratories are not equipped with sophisticated equipment like micro-plate readers, thermal cyclers, etc., and they tend to have only bacterial culture facilities such as incubators and simple microscopes. ${ }^{1,47}$ In these laboratories, routine identification of bacteria and their antibiotic sensitivity is usually carried out by their culture characteristics (less specific) and growth inhibition assays (i.e. analysis of bacterial growth in the presence of antimicrobial agents), which give results in $2-4$ days.

\section{Conclusions}

In the present study, paper-based assays have been devised for the detection of S. aureus and E. coli and their antibiotic resist- ant strains in milk samples, with similar sensitivity to the sophisticated laboratory-based technique, UV-vis spectrophotometry. Employing specific chromogenic substrates, colourchange reactions on $\mu$ PADs have successfully distinguished specific bacteria without cross-reactivity between their $\beta$-lactam susceptible and $\beta$-lactam resistant strains. They also showed, for the first time, a successful differentiation between ESBL resistant and $\beta$-lactam resistant strains. The paper devices showed $\geq 90 \%$ sensitivity and $100 \%$ selectivity, compared to the advanced and sophisticated PCR method, demonstrating a cost-effective platform for the presumptive diagnosis of bacteria in milk, especially in resource limited areas.

\section{Conflicts of interest}

There are no conflicts to declare.

\section{Acknowledgements}

The authors would like to thank the Commonwealth Scholarship Commission, United Kingdom, for providing funding to this project. Dr Fazli Rabbi Awan acknowledges funding (Project No. CRP/PAK14-02; Contract No. CRP/14/012) from the International Centre for Genetic Engineering and Biotechnology (ICGEB), Italy for partial support for research in this study.

\section{References}

1 L. Parsons, A. Somoskovi, C. Gutierrez, E. Lee, C. Paramasivan, A. Abimiku, S. Spector, G. Roscigno and J. Nkengasong, Clin. Microbiol. Rev., 2011, 24, 314-350.

2 S. Oliver, B. Jayarao and R. Almeida, Foodborne Pathog. Dis., 2005, 2, 115-129.

3 M. Pal, S. Mulu, M. Tekle, S. V. Pintoo and J. Prajapati, Beverage Food World, 2016, 43, 1-3.

4 E. Fox, Y. Jiang and K. Gobius, Int. Dairy J., 2018, 84, 28-35.

5 D. Morgan, C. Newman, D. Hutchinson, A. Walker, B. Rowe and F. Majid, Epidemiol. Infect., 1993, 111, 181-187.

6 M. De Buyser, B. Dufour, M. Maire and V. Lafarge, Int. J. Food Microbiol., 2001, 67, 1-17.

7 D. Schmid, R. Fretz, P. Winter, M. Mann, G. Hoger, A. Stoger, W. Ruppitsch, J. Ladstatter, N. Mayer, A. de Martin and F. Allerberger, Wien. Klin. Wochenschr., 2009, 121, 125-131.

8 J. Painter, R. Hoekstra, T. Ayers, R. Tauxe, C. Braden, F. Angulo and P. Griffin, Emerging Infect. Dis., 2013, 19, 407-415.

9 J. E. Hillerton and E. A. Berry, NMC Annual Meeting Proceedings, 2004.

10 US Food and Drug Administration, Compliance Policy Guide Sec. 527.300, 2012.

11 N. Fejzic, M. Begagic, S. Serie-Haracic and M. Smajlovic, Bosnian J. Basic Med. Sci., 2014, 14, 155-159.

12 S. Pyorala, Ir. Vet. J., 2009, 62, 40-44. 
13 T. Ali, S. Rahman, L. Zhang, M. Shahid, S. Zhang, G. Liu, J. Gao and B. Han, Front. Microbiol., 2016, 7, 1931.

14 B. Robles, D. Nobrega, F. Guimaraes, G. Wanderley and H. Langoni, Pesqui. Vet. Brasil, 2014, 34, 325-328.

15 J. Jorgensen and M. Ferraro, Clin. Infect. Dis., 2009, 49, 1749-1755.

16 A. Ashraf, M. Imran, T. Yaqub, M. Tayyab, W. Shehzad and P. Thomson, Mol. Cell. Probes, 2017, 33, 57-64.

17 R. Bu, J. Wang, C. DebRoy, J. Wu, L. Xi, Y. Liu and Z. Shen, Iran J. Vet. Res., 2015, 16, 283-287.

18 C. Rodrigues, N. Desai and H. Fernandes, Clin. Microbiol. Newsl., 2016, 38, 51-56.

19 G. Wu and M. Zaman, Bull. W. H. O., 2012, 90, 914-920.

20 K. Land, D. Boeras, X. Chen, A. Ramsay and R. Peeling, Nat. Microbiol., 2019, 4, 46-54.

21 A. Martinez, S. Phillips, G. Whitesides and E. Carrilho, Anal. Chem., 2010, 82, 3-10.

22 D. Liana, B. Raguse, J. Gooding and E. Chow, Sensors, 2012, 12, 11505-11526.

23 T. Satarpai, J. Shiowatana and A. Siripinyanond, Talanta, 2016, 154, 504-510.

24 K. Abe, K. Suzuki and D. Citterio, Anal. Chem., 2008, 80, 6928-6934.

25 E. Fenton, M. Mascarenas, G. Lopez and S. Sibbett, ACS Appl. Mater. Interfaces, 2009, 1, 124-129.

26 C. Cheng, A. Mazzeo, J. Gong, A. Martinez, S. Phillips, N. Jain and G. Whitesides, Lab Chip, 2010, 10, 3201-3205.

27 Z. Nie, C. Nijhuis, J. Gong, X. Chen, A. Kumachev, A. Martinez, M. Narovlyansky and G. Whitesides, Lab Chip, 2010, 10, 477-483.

28 Y. Lu, W. Shi, L. Jiang, J. Qin and B. Lin, Electrophoresis, 2009, 30, 1497-1500.

29 J. Jokerst, J. Adkins, B. Bisha, M. Mentele, L. Goodridge and C. Henry, Anal. Chem., 2012, 84, 2900-2907.

30 K. Boehle, J. Gilliand, C. Wheeldon, A. Holder, J. Adkins, B. Geiss, E. Ryan and C. Henry, Angew. Chem., Int. Ed., 2017, 56, 6886-6890.
31 B. Bisha, J. Adkins, J. Jokerst, J. Chandler, A. Perez-Mendez, S. Coleman, A. Sbodio, T. Suslow, M. Danyluk, C. Henry and L. Goodridge, J. Vis. Exp., 2014, 51414.

32 D. Lin, B. Li, J. Qi, X. Ji, S. Yang, W. Wang and L. Chen, Sens. Actuators, B, 2020, 303, e51414.

33 M. M. Ajmal, C. X. Li and W. Aslam, J. Econ. Sustain. Dev., 2015, 6, 19-28.

34 H. Hanaki, Y. Koide, H. Yamazaki, R. Kubo, T. Nakano, K. Atsuda and K. Sunakawa, J. Infect. Chemother., 2007, 13, 390-395.

35 M. El-Jade, M. Parcina, R. Schmithausen, C. Stein, A. Meilaender, A. Hoerauf, E. Molitor and I. BekeredjianDing, PLoS One, 2016, 11, 127213.

36 D. Rawat and D. Nair, J. Global Infect. Dis., 2010, 2, 263274.

37 R. Colodner, Am. J. Infect. Control, 2005, 33, 104-107.

38 A. Rambach, US Patent, 6548268B1, 2003.

39 S. Bidya and R. S. Suman, Open J. Clin. Diagn., 2014, 4, 47-52.

40 S. Sharma, P. Ramnani and J. Virdi, J. Antimicrob. Chemother, 2004, 54, 401-405.

41 H. Hanaki, R. Kubo, T. Nakano, M. Kurihara and K. Sunagawa, J. Antimicrob. Chemother, 2004, 53, 888889.

42 S. Jain, J. Andrews, A. Fraise and N. Brenwald, J. Antimicrob. Chemother, 2007, 60, 652-654.

43 D. Livermore, M. Warner and S. Mushtaq, J. Antimicrob. Chemother, 2007, 60, 1375-1379.

44 M. Bruins, P. Juffer, M. Wolfhagen and G. Ruijs, J. Clin. Microbiol., 2007, 45, 682-683.

45 H. Hanaki, Y. Koide, H. Yamazaki, R. Kubo, T. Nakano, K. Atsuda and K. Sunakawa, J. Antimicrob. Chemother, 2007, 13, 390-395.

46 A. Lokur, J. Pharm. Innov., 2018, 7, 103-106.

47 J. Jacobs, L. Hardy, M. Semret, O. Lunguya, T. Phe, D. Affolabi, C. Yansouni and O. Vandenberg, Front. Med., 2019, 6, 205. 